\title{
Adiponectin gene variants and the risk of coronary heart disease: a 16-year longitudinal study
}

\author{
Chloe Y Y Cheung ${ }^{1, *}$, Elaine Y L Hui ${ }^{1,3,}{ }^{*}$, Bernard M Y Cheung ${ }^{1}$, Y C Woo ${ }^{1}$, Aimin Xu ${ }^{1,3}$, \\ Carol H Y Fong ${ }^{1}$, K L Ong ${ }^{1,5}$, C Y Yeung ${ }^{1}$, Edward D Janus ${ }^{6}$, Hung-Fat Tse ${ }^{1,3}$, \\ Pak C Sham ${ }^{2,4,+}$ and Karen S L Lam ${ }^{1,3,+}$ \\ ${ }^{1}$ Department of Medicine, ${ }^{2}$ Department of Psychiatry, ${ }^{3}$ Research Centre of Heart, Brain, Hormone and Healthy \\ Aging and ${ }^{4} \mathrm{Li}$ Ka Shing Faculty of Medicine, Centre for Genomic Sciences, Queen Mary Hospital, The University of \\ Hong Kong, 102 Pokfulam Road, Hong Kong, Hong Kong, ${ }^{5}$ Centre for Vascular Research, University of New South \\ Wales, Sydney, New South Wales 2052, Australia and ${ }^{6}$ Department of Medicine, Northwest Academic Centre, \\ Western Hospital, The University of Melbourne, Melbourne, Victoria, Australia \\ *(C Y Y Cheung and E Y L Hui contributed equally to this work) \\ ${ }^{\dagger}$ (P C Sham and K S L Lam contributed equally to the supervision of this work)
}

Correspondence should be addressed to K S L Lam or P C Sham Email

ksllam@hku.hk or pcsham@hku.hk

\begin{abstract}
Objective: Circulating adiponectin levels have been shown to be associated with a risk of coronary heart disease (CHD). However, its primary role in protecting against the development of CHD remains controversial due to conflicting observations in prospective studies. To gain further insight into the primary role of adiponectin, our major objective was to investigate the relationship between single nucleotide polymorphisms (SNPs) of the adiponectin gene (ADIPOQ) and incident CHD in a population-based cohort with no CHD at baseline.

Design and methods: We conducted a 16-year longitudinal study in 2196 subjects from the Hong Kong Cardiovascular Risk Factor Prevalence Study (CRISPS). During 33862 person-years of follow-up, 184 subjects developed CHD (cumulative incidence rate $=5.4$ per 1000 person-years). Nine ADIPOQ SNPs with potential functional relevance or shown to be associated with adiponectin levels and/or CHD were genotyped.

Results: Among the nine ADIPOQ SNPs, +276G > T (rs1501299) was independently associated with incident CHD in men but not in women, even after adjustments for traditional cardiovascular risk factors $\left(P_{\text {adjusted }}=5.5 \times 10^{-3}\right.$ to 0.023 ; hazard ratio $=1.39-1.54)$. Furthermore, there was a significant association of the $T$ allele of $+276 \mathrm{G}>\mathrm{T}$ with a lower adiponectin level $(P=0.027 ; \beta(95 \% \mathrm{Cl})=-0.05(-0.10,-0.01)$.

Conclusions: This study demonstrated that $+276 \mathrm{G}>\mathrm{T}$ may be an independent predictor of CHD development. Our findings suggest that low adiponectin levels, as may be influenced by $+276 \mathrm{G}>\mathrm{T}$, confer a higher risk of CHD, in keeping with a role of hypoadiponectinaemia in the development of $\mathrm{CHD}$ in the general population.
\end{abstract}

\section{Introduction}

Adiponectin is one of the most abundant insulinsensitising adipokines secreted by the adipocytes (1). Circulating levels of adiponectin are reduced in obesity, in particular visceral obesity $(2,3)$, and they predispose to endothelial dysfunction, atherosclerosis and
(C) 2014 European Society of Endocrinology Printed in Great Britain subsequent cardiovascular diseases (CVDs) in animal models. Hypoadiponectinaemia has been proposed as one of the mediators of increased cardiovascular risk in obesity (4). Adiponectin, encoded by $A D I P O Q$, is suggested to play a protective role in the development of coronary 
heart disease (CHD) due to its anti-inflammatory, antioxidative, anti-apoptotic and anti-atherogenic properties $(3,5)$. The prospective relationship between circulating adiponectin level and the development of CHD has been extensively investigated. However, whether adiponectin levels are causally related to CHD development remains controversial. While high adiponectin levels are believed to be protective against CHD in healthy populations (6), more recent studies have suggested that high adiponectin levels are associated with a greater risk of CHD or cardiovascular mortality in older populations (7) or cohorts with prevalent CHD (8). As the up-regulation of adiponectin could act as a compensatory mechanism to limit further vascular injury (8), a high adiponectin level in the established disease state might reflect on the severity of the underlying vascular inflammation, and hence a positive association between the adiponectin level and cardiovascular mortality.

Studies on potentially functional $A D I P O Q$ genetic variants may provide more insight into the primary role of adiponectin, if any, in protecting against the development of CHD. So far, only a few prospective studies conducted in Caucasians have investigated the genetic effects of $A D I P O Q$ single nucleotide polymorphisms (SNPs) on CHD development $(9,10,11)$. The primary objective of this study was to evaluate the impact of nine $A D I P O Q$ SNPs on the risk of CHD in a 16-year longitudinal study cohort of healthy Southern Chinese. These SNPs were selected because of their potential functional relevance or reported influence on the risk of CHD or CVDs and/or adiponectin levels.

\section{Subjects and methods}

\section{Subjects}

The Hong Kong Cardiovascular Risk Factor Prevalence Study (CRISPS) is a population-based prospective study of cardiovascular risk factors in Hong Kong (12). In 1995-1996 (CRISPS1), 2895 Hong Kong Chinese were selected randomly by their telephone numbers to undergo a comprehensive assessment of cardiovascular risks. Subjects were contacted for reassessment in 2000-2004 (CRISPS2) and 2005-2008 (CRISPS3). The latest CRISPS4 follow-up assessment was commenced in July 2010. The current study involved a total of 2196 subjects who did not have a history of CHD at baseline (CRISPS1) and with their DNA samples available for genetic analysis. During 33862 person-years of follow-up, 184 subjects ( 111 men and 73 women) who were without
CHD at baseline had developed CHD by the end of 2011, giving a cumulative incidence rate of 5.4 per 1000 person-years. A total of 2012 subjects (915 men and 1097 women) who were without CHD at baseline had remained without $\mathrm{CHD}$ at subsequent follow-up visit(s). CHD events were defined based on ICD-9 (402, 404, 410-414, 425-429), which included, among others, acute myocardial infarction (MI), heart failure and angina pectoris as described in our previous study (13). Information on the dates of the CHD events and discharge diagnosis were obtained from the patients and also verified from the hospital authority database or the patients' private practitioners. For those who had died, causes and dates of death were determined from the Hong Kong Death Registry database. Two physicians reviewed the medical diagnoses independently and disagreements between them were resolved by a third physician. The concordance between the two physicians was 0.98 . Written informed consent was obtained from each participant and the study protocol was approved by the Ethics Committee of the University of Hong Kong.

\section{Anthropometric and biochemical measurements}

Anthropometric (including BMI, waist circumference (WC), systolic blood pressure (SBP) and diastolic blood pressure (DBP)) and biochemical parameters (including fasting plasma glucose (FPG), 2-h post-OGTT glucose (2hrG), triglyceride (TG), HDL-C, LDL-C and total cholesterol (TC)) were measured as described previously (14). Type 2 diabetes (DM) was defined as FPG $\geq 7.0 \mathrm{mmol} / \mathrm{l}$ or $2 \mathrm{hrG} \geq 11.1 \mathrm{mmol} / \mathrm{l}$ or both, according to the World Health Organization 1998 diagnostic criteria (15) or on anti-diabetic medication. At baseline, 181 subjects (89 men and 90 women) had DM and 1923 subjects (904 men and 1017 women) were without DM. The presence of hypertension (HT) was indicated by $\mathrm{BP} \geq 140 / 90 \mathrm{mmHg}$ or if the patient was receiving regular anti-hypertensive treatment. The presence of dyslipidaemia was indicated by fasting TG $\geq 1.69 \mathrm{mmol} / \mathrm{l}$, HDL-C $<1.04 \mathrm{mmol} / \mathrm{l}$ in males and $<1.29 \mathrm{mmol} / \mathrm{l}$ in females, and LDL-C $\geq 3.4 \mathrm{mmol} / \mathrm{l}$ (16) or if the patient was taking lipidlowering agents. As stored baseline plasma samples were no longer available from a large number of subjects, total adiponectin level was measured from available plasma samples collected during the CRISPS2 follow-up visit ( $n=1676)$, using an in-house sandwich ELISA kit established in our laboratory (intra- and inter-assay coefficient of variation values of $6.2-8.3$ and $5.1-6.4 \%$ respectively) (17). 


\section{Genetic analysis}

A total of nine ADIPOQ SNPs (rs16861194, rs266729 $(-11377 \mathrm{C}>\mathrm{G}),-10677 \mathrm{C}>\mathrm{T}, \mathrm{rs} 1802052(-10066 \mathrm{G}>\mathrm{A})$, rs822395 $(-4034 \mathrm{~A}>\mathrm{C}), \quad \operatorname{rs822396}(-3964 \mathrm{~A}>\mathrm{G})$, rs12495941, rs2241766 $(+45 \mathrm{~T}>\mathrm{G})$ and rs1501299 $(+276 \mathrm{G}>\mathrm{T}))$ were selected on the basis of previous publications suggesting them as functional $(18,19,20)$, or shown to affect adiponectin levels $(9,21,22,23)$, or associated with $\operatorname{CHD} / \operatorname{CVD}(9,11,24)$. Genotyping of these SNPs was carried out using the Sequenom iPLEX Gold genotyping assay at the Centre for Genomic Sciences, the University of Hong Kong. The average genotyping call rate and concordance rate were 99.8 and $97.5 \%$ respectively. The SNPs were tested for deviation from the HardyWeinberg Equilibrium (HWE) by the de Finetti program available online at <http://ihg2.helmholtz-muenchen. de/cgi-bin/hw/hwa1.pl $>$.

\section{Statistical analyses}

All statistical analyses were conducted using SPSS version 19.0. The associations of SNPs with incident CHD were evaluated using Cox proportional hazards regression (Cox regression) analyses under the additive model. Survival was calculated from the date of visit at baseline to the date of diagnosis of CHD or the date of last follow-up visit. In view of the known gender difference in adiponectin levels (25) and the observation of a higher incidence rate of CHD in men (7.1 per 1000 person-years vs 4.0 per 1000 personyears in women), we also performed gender-stratified analyses. A two-tailed $P<0.05$ was considered statistically significant. Baseline clinical parameters that were biologically likely to have an influence on the development of CHD or were statistically different $(P<0.05)$ between the incident $\mathrm{CHD}$ and non-CHD groups were adjusted for in the multiple adjustment analyses. Three different sets of traditional risk factors were included in the multiple Cox regression analyses. Multiple adjustments for age, BMI, 2hrG, HOMA-IR, HDL-C, LDL-C, TG, SBP, DBP and smoking were made in Model 1; adjustments were made for age, BMI, FPG, 2hrG, HDL-C, LDL-C, TG, SBP, DBP and smoking in Model 2 and adjustments were made for age, BMI, DM, dyslipidaemia, HT and smoking in Model 3. Logistic regression analysis was employed to examine the association of $+276 \mathrm{G}>\mathrm{T}$ with $\mathrm{DM}$ at baseline. The association of $+276 \mathrm{G}>\mathrm{T}$ with plasma adiponectin level at CRISPS2 was evaluated by linear regression analysis. The associations of CRISPS2 adiponectin levels with the development of CHD were evaluated using Cox regression analyses. Survival was calculated from the date of visit at CRISPS2 to the date of diagnosis of CHD or the date of last follow-up visit. Both combined and gender-stratified analyses were carried out. The study power was calculated using the Genetic Power Calculator (26).

\section{Results}

\section{Baseline clinical characteristics}

We examined the associations of nine $A D I P O Q$ genetic variants with incident CHD in 2196 subjects with DNA samples available for genetic analysis. Among these subjects who were without CHD at baseline, 184 subjects (cumulative incidence rate $=5.4$ per 1000 person-years) developed CHD during 33862 person-years of follow-up; 2012 subjects remained free of CHD at subsequent followup visit(s). Table 1 shows the baseline clinical characteristics of the subjects. In both genders, the incident CHD groups had worse traditional cardiovascular risk factors, such as the presence of DM, dyslipidaemia and HT, when compared with the non-CHD groups. However, there were no significant differences in regular exercise, alcohol drinking and family history of DM, HT and CHD.

\section{Association with CHD development}

The allele frequencies of the nine SNPs were comparable to those reported in HapMap or 1000 Genome Project (Table 2). The genotype distributions of these SNPs were in HWE $(P=0.071-0.809)$. Among these SNPs, rs1501299 $(+276 \mathrm{G}>\mathrm{T})$ showed a significant association with incident CHD $\left(P_{\text {unadjusted }}=0.042\right.$; hazard ratio $(\mathrm{HR})(95 \% \mathrm{CI})$ : $1.26(1.01-1.56))$. When stratified by gender, the association of $+276 \mathrm{G}>\mathrm{T}$ variant with incident $\mathrm{CHD}$ remained significant in men $\left(P_{\text {unadjusted }}=0.020\right.$; HR $(95 \% \mathrm{CI})=1.39$ (1.05-1.83)). However, no significant association was found in women $\left(P_{\text {unadjusted }}=0.816\right.$; HR $(95 \% \mathrm{CI})=1.04$ (0.73-1.50)). No significant associations of the other SNPs with incident CHD were observed in either gender.

\section{Independent association of $+\mathbf{2 7 6 G}>\mathbf{T}$ with incident CHD in men}

The possible independent association of $+276 \mathrm{G}>\mathrm{T}$ with incident CHD in men was further analysed with adjustments for different sets of traditional risk factors, including $\mathrm{DM}$ and its related traits, as the $+276 \mathrm{G}>\mathrm{T}$ variant was independently associated with $\mathrm{DM}$ at baseline, even after adjustment for age, sex and BMI in this study 
Table 1 Baseline clinical characteristics of subjects. Data are expressed as mean \pm s.D. or median with interquartile range.

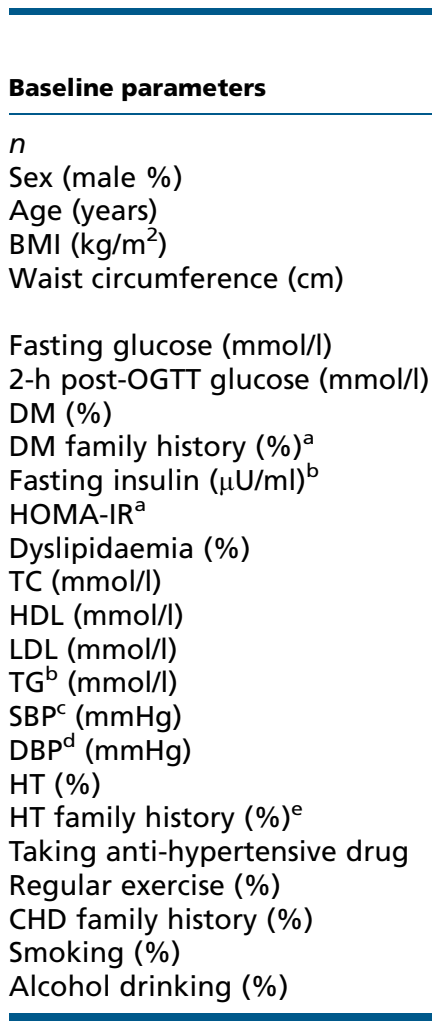

\begin{tabular}{ccc}
\hline \multicolumn{2}{c}{ All } \\
\cline { 1 - 2 } Non-CHD & & Incident CHD \\
\cline { 1 - 1 } 2012 & & 184 \\
45.5 & & $60.3^{*}$ \\
$44.4 \pm 11.7$ & & $56.3 \pm 10.9^{*}$ \\
$24.0 \pm 3.6$ & & $25.8 \pm 3.3^{*}$ \\
M: $82.6 \pm 9.1$ & & M: $88.1 \pm 9.5^{*}$ \\
$\mathrm{~F}: 74.8 \pm 9.0$ & & $\mathrm{~F}: 82.5 \pm 8.4^{*}$ \\
$5.3 \pm 1.1$ & & $6.1 \pm 2.3^{\dagger}$ \\
$6.6 \pm 2.7$ & & $8.5 \pm 5.0^{*}$ \\
7.1 & & $24.5^{*}$ \\
17.4 & & 13.7 \\
$4.8(3.1-7.3)$ & & $5.7(3.9-9.0)^{*}$ \\
$1.1(0.7-1.7)$ & & $1.5(1.0-2.3)^{*}$ \\
62.4 & & $82.1^{*}$ \\
$5.0 \pm 1.0$ & & $5.4 \pm 1.0^{*}$ \\
$1.3 \pm 0.3$ & & $1.2 \pm 0.3^{*}$ \\
$3.2 \pm 0.9$ & & $3.6 \pm 1.0^{*}$ \\
$1.0(0.7-1.4)$ & & $1.3(0.9-1.9)^{\dagger}$ \\
$117.6 \pm 18.9$ & & $135.1 \pm 23.3^{*}$ \\
$74.1 \pm 10.7$ & & $81.2 \pm 11.9^{*}$ \\
14.1 & $48.4^{*}$ \\
29.4 & & 24.0 \\
3.2 & & $12.4^{*}$ \\
41.5 & & 44.6 \\
10.4 & & 13.8 \\
22.6 & & $37.2^{*}$ \\
36.1 & & 42.9 \\
& &
\end{tabular}

\begin{tabular}{c}
\hline \multicolumn{1}{c}{ Mal } \\
\hline Non-CHD \\
\hline 915 \\
- \\
$44.9 \pm 12.3$ \\
$24.3 \pm 3.3$ \\
$82.5 \pm 9.1$ \\
$5.4 \pm 1.3$ \\
$6.5 \pm 3.1$ \\
7.8 \\
15.9 \\
$3.0(2.0-4.6)$ \\
$0.7(0.4-1.1)$ \\
61.9 \\
$5.1 \pm 1.1$ \\
$1.2 \pm 0.3$ \\
$3.3 \pm 0.8$ \\
$1.1(0.8-1.6)$ \\
$120.0 \pm 17.0$ \\
$76.6 \pm 10.0$ \\
14.8 \\
28.7 \\
3.2 \\
44.8 \\
10.9 \\
45.5 \\
56.1 \\
\hline
\end{tabular}

Male

Incident CHD

111

$55.6 \pm 10.8 *$

$25.8 \pm 3.3^{*}$

$88.1 \pm 9.5$ *

$5.8 \pm 1.8^{\dagger}$

$7.9 \pm 4.4^{*}$

$18.9 *$

9.2

$3.7(2.6-5.3)^{\dagger}$

$0.9(0.6-1.3)^{\dagger}$

79.3*

$5.3 \pm 0.9$ *

$1.1 \pm 0.3^{\dagger}$

$3.5 \pm 0.8$

$1.4(1.0-2.0)^{\dagger}$

$133.3 \pm 21.2^{*}$

$81.6 \pm 12.4$ *

45.9 *

20.9

$8.8^{\dagger}$

47.7

5.5

$56.8^{\dagger}$

59.1

\begin{tabular}{|c|c|}
\hline \multicolumn{2}{|c|}{ Female } \\
\hline Non-CHD & Incident CHD \\
\hline 1097 & 73 \\
\hline- & - \\
\hline $44.0 \pm 11.2$ & $57.2 \pm 11.0$ * \\
\hline $23.9 \pm 3.7$ & $25.8 \pm 3.3^{*}$ \\
\hline $74.8 \pm 9.0$ & $82.5 \pm 8.4^{*}$ \\
\hline $5.2 \pm 0.9$ & $6.6 \pm 2.9^{\dagger}$ \\
\hline $6.7 \pm 2.4$ & $9.4 \pm 5.9 *$ \\
\hline 6.5 & $32.9 *$ \\
\hline 18.6 & 20.5 \\
\hline $3.3(2.3-5.0)$ & $5.1(3.1-6.9) *$ \\
\hline $0.7(0.5-1.1)$ & $1.2(0.7-1.8)$ * \\
\hline 62.9 & $86.3 *$ \\
\hline $4.9 \pm 1.0$ & $5.6 \pm 1.1$ * \\
\hline $1.4 \pm 0.3$ & $1.3+0.3^{\dagger}$ \\
\hline $3.1 \pm 0.9$ & $3.7 \pm 1.1 *$ \\
\hline $0.6(0.5-0.9)$ & $0.9(0.6-1.1)^{\dagger}$ \\
\hline $115.5 \pm 20.0$ & $137.8 \pm 25.9 *$ \\
\hline $72.0 \pm 10.9$ & $80.5 \pm 11.0 *$ \\
\hline 13.6 & $52.1 *$ \\
\hline 30.1 & 28.8 \\
\hline 3.3 & $17.9 *$ \\
\hline 38.7 & 39.7 \\
\hline 16.2 & 17.8 \\
\hline 3.5 & 6.9 \\
\hline 19.4 & 18.1 \\
\hline
\end{tabular}

${ }^{*} P$ value $<0.001 ;{ }^{\dagger} P$ value $<0.05$. CHD, coronary heart disease; DBP, diastolic blood pressure; DM, type 2 diabetes; $F$, female; HOMA-IR, homoeostasis mode assessment index of insulin resistance; HT, hypertension; M, male; n, number; SBP, systolic blood pressure; TC, total cholesterol; TG, triglyceride.

a Diabetes in first-degree relatives.

batural log transformed before analysis.

${ }^{\mathrm{S}} \mathrm{SBP}+10 \mathrm{mmHg}$ if on anti-hypertensive drug.

${ }^{\mathrm{d}} \mathrm{DBP}+5 \mathrm{mmHg}$ if on anti-hypertensive drug

${ }^{\mathrm{e}}$ Hypertension in first-degree relatives.

$\left(P_{\text {age, }}\right.$ sex and BMI adjusted $=2 \times 10^{-3} ;$ OR $(95 \% \mathrm{CI})=1.45$ (1.14-1.84)). Table 3 shows the results of the multiple Cox regression analyses in the male subjects. After adjustment for age, BMI, 2hrG, HOMA-IR, HDL-C, LDL-C, TG, SBP, DBP and smoking (Model 1), $+276 \mathrm{G}>\mathrm{T}$ showed a significant association with incident $\mathrm{CHD}$ in men $\left(P_{\text {adjusted }}=\right.$ $\left.5.5 \times 10^{-3} ; \operatorname{HR}(95 \% \mathrm{CI})=1.54(1.13-2.08)\right)$. Figure 1 shows the cumulative survival curves for incident $\mathrm{CHD}$ in men, based on multiple adjustment Model 1 and stratified by the $+276 \mathrm{G}>\mathrm{T}$ genotypes. Male subjects with the TT genotype had a significantly higher risk of developing CHD than those with the GG or GT genotypes as shown in Fig. $1\left(P_{\text {adjusted }}=5.5 \times 10^{-3}\right)$. The association was also significant in adjustment Model 2 ( $P_{\text {age, BMI, FPG, }}$ 2hrG, HDL-C, LDL-C, TG, SBP, DBP and smoking adjusted $=0.015$; HR $(95 \%$ CI $)=1.44(1.08-1.93))$. Furthermore, when the presence of DM, dyslipidaemia and HT were included in the adjustment model in addition to age, BMI and smoking (Model 3), the association persisted $\left(P_{\text {adjusted }}=\right.$ 0.023; HR $(95 \% \mathrm{CI})=1.39(1.05-1.84))$. By contrast, as expected, no significant association of $+276 \mathrm{G}>\mathrm{T}$ with incident $\mathrm{CHD}$ was observed in women (Model 1: $P_{\text {adjusted }}=0.539, \quad \operatorname{HR} \quad(95 \% \quad \mathrm{CI})=0.88 \quad(0.58-1.33)$; Model 2: $P_{\text {adjusted }}=0.381$, HR $(95 \% \mathrm{CI})=0.83(0.56-1.13)$; Model 3: $P_{\text {adjusted }}=0.339$, HR $\left.(95 \% \mathrm{CI})=0.84(0.58-1.21)\right)$.

\section{Association of the $+276 \mathrm{G}>\mathrm{T}$ variant with plasma adiponectin level at CRISPS2}

Adiponectin level was found to be significantly lower $(P<0.001)$ in men (median (interquartile range $)=5.62$ (3.62-8.69) $\mathrm{mg} / 1, n=804)$ than in women (7.89 (5.3711.78) $\mathrm{mg} / \mathrm{l}, n=872$ ). We observed a significant association of the $\mathrm{T}$ allele of $+276 \mathrm{G}>\mathrm{T}$ with a lower adiponectin level $(P=0.027 ; \beta(95 \% \mathrm{CI})=-0.05(-0.10$, -0.01)) in 1676 subjects with available plasma samples. When the association was examined in men and women separately, we observed a significant association in men $(P=0.049 ; \beta(95 \% \mathrm{CI})=-0.07(-0.14,0.00))$, but the association was not significant in women $(P=0.424$; 
Table 2 Genotype distributions and results of Cox regression analyses.

\begin{tabular}{l}
\hline \\
SNP (1/2) \\
\hline rs1501299 (+276G $>$ T) (G/T) \\
All \\
M \\
F \\
rs2241766 (T/G) \\
All \\
M \\
F \\
rs12495941 (G/T) \\
All \\
M \\
F \\
rs822396 (A/C) \\
All \\
M \\
F \\
rs822395 (A/C) \\
All \\
M \\
F \\
rs182052 (G/A) \\
All \\
M \\
F \\
- 10677C $>T^{b}(C / T)$ \\
All \\
M \\
F \\
rs266729 (C/G) \\
All \\
M \\
F \\
rs16861194 (A/G) \\
All \\
M \\
F \\
\end{tabular}

\begin{tabular}{|c|c|}
\hline \multicolumn{2}{|c|}{ Genotype distribution } \\
\hline Non-CHD (11/12/22) & Incident CHD (11/12/22) \\
\hline $\begin{array}{c}1103 / 759 / 148 \\
500 / 343 / 71 \\
603 / 416 / 77\end{array}$ & $\begin{array}{c}88 / 75 / 19 \\
46 / 52 / 11 \\
42 / 23 / 8\end{array}$ \\
\hline $\begin{array}{c}1007 / 822 / 183 \\
466 / 371 / 78 \\
541 / 451 / 105\end{array}$ & $\begin{array}{c}89 / 83 / 12 \\
56 / 52 / 3 \\
33 / 31 / 9\end{array}$ \\
\hline $\begin{array}{l}680 / 966 / 362 \\
327 / 417 / 168 \\
353 / 549 / 194\end{array}$ & $\begin{array}{l}56 / 95 / 32 \\
31 / 58 / 21 \\
25 / 37 / 11\end{array}$ \\
\hline $\begin{array}{c}1511 / 468 / 30 \\
688 / 213 / 13 \\
823 / 255 / 17\end{array}$ & $\begin{array}{l}137 / 46 / 1 \\
84 / 26 / 1 \\
53 / 20 / 0\end{array}$ \\
\hline $\begin{array}{c}1441 / 527 / 41 \\
654 / 243 / 16 \\
787 / 284 / 25\end{array}$ & $\begin{array}{l}130 / 53 / 1 \\
81 / 29 / 1 \\
49 / 24 / 0\end{array}$ \\
\hline $\begin{array}{l}698 / 966 / 342 \\
319 / 436 / 157 \\
379 / 530 / 185\end{array}$ & $\begin{array}{l}64 / 93 / 25 \\
41 / 53 / 15 \\
23 / 40 / 10\end{array}$ \\
\hline $\begin{array}{l}1755 / 248 / 8 \\
797 / 114 / 4 \\
958 / 134 / 4\end{array}$ & $\begin{array}{c}156 / 25 / 3 \\
90 / 20 / 1 \\
66 / 5 / 2\end{array}$ \\
\hline $\begin{array}{c}1148 / 729 / 130 \\
512 / 347 / 53 \\
636 / 382 / 77\end{array}$ & $\begin{array}{l}111 / 65 / 8 \\
67 / 40 / 4 \\
44 / 25 / 4\end{array}$ \\
\hline $\begin{array}{c}1410 / 543 / 59 \\
642 / 248 / 25 \\
768 / 295 / 34\end{array}$ & $\begin{array}{l}128 / 50 / 6 \\
80 / 28 / 3 \\
48 / 22 / 3\end{array}$ \\
\hline
\end{tabular}

\begin{tabular}{|c|c|}
\hline \multicolumn{2}{|c|}{ MAF } \\
\hline Non-CHD & Incident CHD \\
\hline 0.262 & 0.310 \\
\hline 0.265 & 0.339 \\
\hline 0.260 & 0.267 \\
\hline 0.295 & 0.290 \\
\hline 0.288 & 0.261 \\
\hline 0.301 & 0.336 \\
\hline 0.421 & 0.434 \\
\hline 0.412 & 0.455 \\
\hline 0.427 & 0.404 \\
\hline 0.131 & 0.130 \\
\hline 0.131 & 0.126 \\
\hline 0.132 & 0.137 \\
\hline 0.151 & 0.149 \\
\hline 0.151 & 0.139 \\
\hline 0.152 & 0.164 \\
\hline 0.411 & 0.393 \\
\hline 0.411 & 0.381 \\
\hline 0.411 & 0.411 \\
\hline 0.066 & 0.084 \\
\hline 0.067 & 0.099 \\
\hline 0.065 & 0.054 \\
\hline 0.246 & 0.220 \\
\hline 0.248 & 0.216 \\
\hline 0.245 & 0.226 \\
\hline 0.164 & 0.168 \\
\hline 0.162 & 0.153 \\
\hline 0.165 & 0.191 \\
\hline
\end{tabular}

\begin{tabular}{|c|c|}
\hline \multicolumn{2}{|c|}{ Unadjusted } \\
\hline HR $(95 \% \mathrm{Cl})$ & $P$ value \\
\hline $1.26(1.01-1.56)$ & 0.042 \\
\hline $1.39(1.05-1.83)$ & $0.020^{a}$ \\
\hline $1.04(0.73-1.50)$ & 0.816 \\
\hline $0.97(0.78-1.22)$ & 0.813 \\
\hline $0.87(0.65-1.18)$ & 0.374 \\
\hline $1.16(0.82-1.62)$ & 0.401 \\
\hline $1.05(0.86-1.29)$ & 0.633 \\
\hline $1.15(0.89-1.50)$ & 0.278 \\
\hline $0.91(0.65-1.27)$ & 0.592 \\
\hline $0.99(0.73-1.35)$ & 0.955 \\
\hline $0.97(0.65-1.45)$ & 0.878 \\
\hline $1.04(0.64-1.67)$ & 0.884 \\
\hline $0.98(0.73-1.31)$ & 0.900 \\
\hline $0.92(0.63-1.36)$ & 0.674 \\
\hline $1.08(0.70-1.68)$ & 0.720 \\
\hline $0.93(0.76-1.15)$ & 0.510 \\
\hline $0.89(0.68-1.17)$ & 0.400 \\
\hline $1.00(0.72-1.39)$ & 0.992 \\
\hline $1.26(0.87-1.83)$ & 0.225 \\
\hline $1.48(0.96-2.30)$ & 0.078 \\
\hline $0.86(0.42-1.75)$ & 0.671 \\
\hline $0.88(0.69-1.12)$ & 0.288 \\
\hline $0.84(0.61-1.16)$ & 0.298 \\
\hline $0.92(0.63-1.34)$ & 0.653 \\
\hline $1.03(0.78-1.34)$ & 0.854 \\
\hline $0.94(0.65-1.35)$ & 0.723 \\
\hline $1.17(0.78-1.76)$ & 0.438 \\
\hline
\end{tabular}

All significant associations are highlighted in bold.

1, Major allele; 2 , minor allele; $F$, female; $M$, male; MAF, minor allele frequency. aRemained significant after adjustment for age and BMI.

${ }^{\mathrm{b}}$ No rs number is assigned for this SNP.

$\beta(95 \% \mathrm{CI})=-0.03(-0.09,0.04))$. Supplementary Table 1 , see section on supplementary data given at the end of this article, shows the comparison of adiponectin levels at CRISPS2 between different genotypes of $+276 \mathrm{G}>\mathrm{T}$. Similar findings were obtained when subjects who had developed CHD by CRISPS2 were excluded.

\section{Association of plasma adiponectin level at CRISPS2 with the development of CHD after a median interval of $\sim 9.6$ years}

We further examined the association of plasma adiponectin levels at CRISPS2 with the development of CHD, after a median interval of $\sim 9.6$ years. As 46 of the 1676 subjects with adiponectin levels available for analysis had developed CHD by CRISPS2, only 1630 subjects were included in the analysis. Over a median interval of 9.6 years, 101 subjects (56 men and 45 women) had developed CHD, while 1529 subjects (720 men and 809 women) remained free of CHD. We did not observe any significant association between CRISPS2 adiponectin level and CHD development, in both the combined $(P=0.200$; HR $(95 \% \mathrm{CI})=0.82(0.60-1.11))$ and genderstratified analyses (men: $P=0.465$, HR $(95 \% \mathrm{CI})=0.85$ (0.60-1.30); women: $P=0.665$, HR $(95 \% \quad \mathrm{CI})=0.89$ $(0.54-1.48))$. 
Table 3 Multiple Cox regression analyses of $A D I P O Q+276 \mathrm{G}>$ T and incident CHD in the male subjects.

\begin{tabular}{|c|c|c|c|c|c|c|}
\hline \multirow[b]{2}{*}{ Risk factors } & \multicolumn{2}{|c|}{ Model 1} & \multicolumn{2}{|c|}{ Model 2} & \multicolumn{2}{|c|}{ Model 3} \\
\hline & $\mathrm{HR}(95 \% \mathrm{Cl})$ & $P$ value & $\mathrm{HR}(95 \% \mathrm{Cl})$ & $P$ value & $\mathrm{HR}(95 \% \mathrm{Cl})$ & $P$ value \\
\hline$+276 \mathrm{G}>\mathrm{T}(\mathrm{T})$ & $1.54(1.13-2.08)$ & $5.5 \times 10^{-3}$ & $1.44(1.08-1.93)$ & 0.015 & 1.39 (1.05-1.84) & 0.023 \\
\hline Age (years) & $1.06(1.04-1.08)$ & $<0.001$ & $1.06(1.04-1.08)$ & $<0.001$ & $1.06(1.04-1.08)$ & $<0.001$ \\
\hline BMI $\left(\mathrm{kg} / \mathrm{m}^{2}\right)$ & $1.07(1.00-1.15)$ & 0.044 & $1.08(1.02-1.15)$ & 0.010 & $1.10(1.03-1.16)$ & 0.002 \\
\hline DM & - & - & - & - & $1.01(0.61-1.68)$ & 0.976 \\
\hline FPG (mmol/l) & - & - & $1.11(0.90-1.37)$ & 0.331 & - & - \\
\hline $2 \mathrm{hrG}(\mathrm{mmol} / \mathrm{l})$ & $1.00(0.95-1.05)$ & 0.954 & $0.98(0.90-1.06)$ & 0.562 & - & - \\
\hline HOMA-IR & $1.06(0.77-1.48)$ & 0.711 & - & - & - & - \\
\hline Dyslipidaemia & - & - & - & - & $1.43(0.89-2.31)$ & 0.143 \\
\hline $\mathrm{HDL}-\mathrm{C}(\mathrm{mmol} / \mathrm{l})$ & $0.62(0.26-1.50)$ & 0.292 & $0.57(0.24-1.32)$ & 0.188 & - & - \\
\hline LDL-C (mmol/l) & $0.91(0.71-1.17)$ & 0.467 & $0.92(0.73-1.17)$ & 0.504 & - & - \\
\hline TG $(\mathrm{mmol} / \mathrm{l})^{\mathrm{a}}$ & $1.40(0.85-2.31)$ & 0.187 & $1.40(0.86-2.28)$ & 0.177 & - & - \\
\hline HT & - & - & - & - & $2.03(1.31-3.14)$ & 0.002 \\
\hline $\mathrm{SBP}^{\mathrm{b}}(\mathrm{mmHg})$ & $1.01(0.99-1.03)$ & 0.237 & $1.02(1.00-1.03)$ & 0.088 & - & - \\
\hline $\mathrm{DBP}^{\mathrm{b}}(\mathrm{mmHg})$ & $1.01(0.97-1.04)$ & 0.744 & $1.00(0.97-1.03)$ & 0.791 & - & - \\
\hline Smoking & $1.25(0.96-1.88)$ & 0.278 & $1.30(0.88-1.92)$ & 0.183 & $1.82(0.88-1.91)$ & 0.185 \\
\hline
\end{tabular}

All significant associations are highlighted in bold.

Model 1: multiple adjustments made for age, BMI, 2hrG, HOMA-IR, HDL-C, LDL-C, TG, SBP, DBP and smoking. Model 2: multiple adjustments made for age, BMI, FPG, 2hrG, HDL-C, LDL-C, TG, SBP, DBP and smoking. Model 3: multiple adjustments made for age, BMI, DM, dyslipidaemia, HT and smoking. 2hrG, 2-h post-OGTT glucose; DM, type 2 diabetes; DBP, diastolic blood pressure; FPG, fasting plasma glucose; HOMA-IR, homoeostasis model assessment index of insulin resistance; HR, hazard ratio; HT, hypertension; SBP, systolic blood pressure; TG, triglyceride.

a Natural log transformed before analysis.

${ }^{\mathrm{b}} \mathrm{SBP}+10 \mathrm{mmHg}$ and $\mathrm{DBP}+5 \mathrm{mmHg}$ if on anti-hypertensive drug

\section{Discussion}

In this study, we observed a significant association of $+276 \mathrm{G}>\mathrm{T}$ with $\mathrm{CHD}$ development in men in a general population, independent of conventional cardiovascular risk factors. Consistent with previous cross-sectional studies $(27,28,29)$, the $+276 \mathrm{G}>\mathrm{T}$ variant showed a significant association with DM in our cohort. The current study demonstrated that the $+276 \mathrm{G}>\mathrm{T}$ variant was independently associated with incident CHD in men, even after adjustment for DM or its related traits, together with other potential confounding factors, in the different multiple adjustment models. We also observed that $+276 \mathrm{G}>\mathrm{T}$ was associated with a lower plasma adiponectin level in this Chinese population, as reported previously in studies among Italians (21) and Greeks (23). Our findings suggest that low adiponectin levels, as influenced by a genetic variant in the $A D I P O Q$ gene, confer a higher risk of $\mathrm{CHD}$, in keeping with a role of low circulating adiponectin levels in the development of CHD.

The $\mathrm{T}$ allele of $+276 \mathrm{G}>\mathrm{T}$ had previously been found to be associated with CHD in case-control cross-sectional studies among Chinese (24), Italians (21) and Greeks (23). The current study has further provided evidence for its association with an increased risk of developing CHD in a population-based cohort, likely through a reduction in adiponectin expression. Intriguingly, a significant association of the $+276 \mathrm{G}>\mathrm{T}$ variant with incident $\mathrm{CHD}$ was only present in the male subjects of our cohort. The differences in cardiovascular risk profile between the two genders, such as lipid levels and blood pressure, may have contributed to the observed gender-specific association.

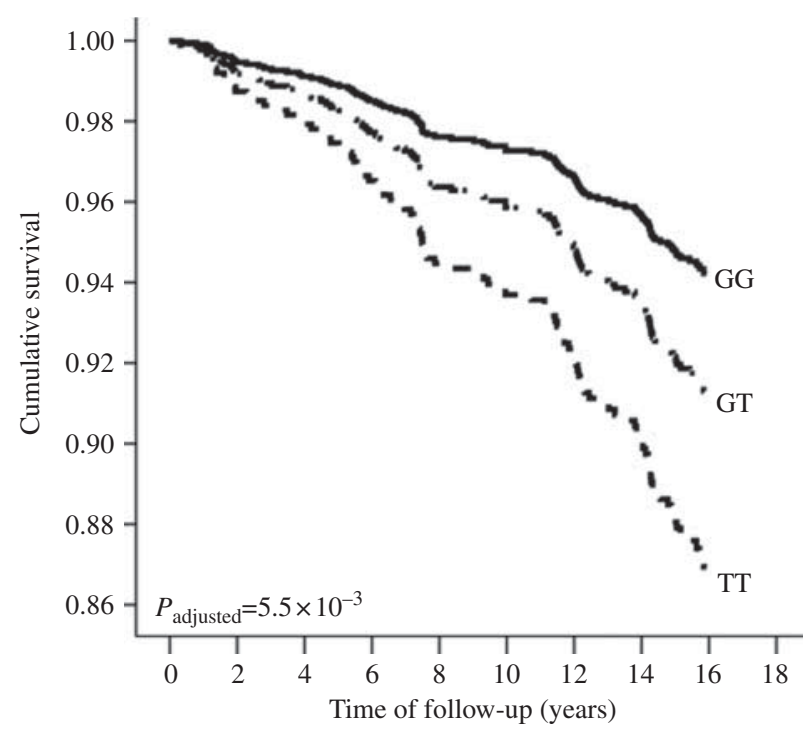

\section{Figure 1}

The cumulative survival curves for incident CHD in men, based on multiple Cox regression Model 1, with adjustment for age, BMI, 2hrG, HOMA-IR, HDL-C, LDL-C, TG, SBP, DBP and smoking. The cumulative survival curves were stratified by the $+276 \mathrm{G}>\mathrm{T}$ genotypes. 
The higher CHD incidence rate in men (7.1 per 1000 person-years) compared with women (4.0 per 1000 person-years) may also be a contributing factor. The lack of a significant association in women might have been attributable to the smaller number of new CHD events. Adiponectin levels were known to be higher in women and later decline with abdominal adiposity, which also show gender-specific differences $(25,30)$. Indeed, adiponectin level was found to be higher in the female subjects of our cohort. Gender-specific differences in adiponectin levels have been shown to be strongly associated with serum androgen levels (25). Our group has previously demonstrated that testosterone selectively decreased the circulating concentrations of the high-molecular-weight form of adiponectin by impeding its secretion from the adipose tissue (17). Androgens have been shown to decrease plasma adiponectin and the androgen-induced hypoadiponectinaemia may lead to a higher risk of atherosclerosis in men (31). The unfavourable consequences of lower adiponectin levels could possibly lead to a higher risk of developing CHD in men than in women. Therefore, the genetic effect of $A D I P O Q$ might be more readily detected in the high-risk male subjects.

In this long-term longitudinal study, we have demonstrated the independent association of ADIPOQ +276G $>\mathrm{T}$ with incident $\mathrm{CHD}$ in a general population. From previous prospective studies that examined the genetic effect of $+276 \mathrm{G}>\mathrm{T}$ on $\mathrm{CHD}(11)$ or $\mathrm{CVD}(9,10)$ development, a US study based on diabetic men reported a significant association of this SNP with CVD development (9). In contrast to our findings, they reported that the $\mathrm{T}$ allele was associated with a lower risk of CVDs and increased adiponectin level (9). This discrepancy may be explained by the difference in inclusion criteria (subjects from the general population vs all DM patients and study endpoints (CHD vs CVD)). Two other longitudinal studies $(10,11)$ did not detect a significant association of $+276 \mathrm{G}>\mathrm{T}$, but reported significant associations of rs266729 and rs17300539 (monomorphic in Han Chinese), with CVD development (10) and rs822395 with CHD risk (11). However, no significant associations of rs266729 and rs822395 were detected in this study. Ethnic differences in genetic composition and interaction, together with distinct environmental factors, may contribute to these variations in findings.

The $+276 \mathrm{G}>\mathrm{T}$ variant was located within intron 2 of $A D I P O Q$. The biological significance of this SNP and the mechanism through which this variant leads to altered adiponectin levels have not been fully elucidated. We postulated that it may potentially affect the transcriptional activity or the splicing efficiency of the ADIPOQ gene. Previous studies have demonstrated that intronic polymorphisms can influence the transcription activity or splicing processes, even when the variants are located more than $30 \mathrm{bp}$ away from the nearest splice junction (32). Intronic splicing control elements, which are involved in recognition of the appropriate splice site or in regulation of the splice site usage, have been found as far as $200 \mathrm{bp}$ away from the splice site (33). Therefore, the $+276 \mathrm{G}>\mathrm{T}$ variant, which is located $\sim 60 \mathrm{bp}$ away from the nearest splice junction, may potentially affect the splicing efficiency. Future functional studies would be helpful to delineate the effect of this variant on adiponectin protein expression.

This study has several limitations. The relatively small number of incident CHD cases, despite the long follow-up period, has made this study slightly underpowered. Nonetheless, the current sample size could achieve over $80 \%$ power to detect a significant association of $+276 \mathrm{G}>\mathrm{T}$ with a large effect size of 1.54 in men, at a significance level of 0.05. On the other hand, the effects of the other ADIPOQ SNPs may be too modest for a significant association to be detected. This study was limited by the small number of hard endpoint cases, such as MI, and has therefore made it difficult for a definitive conclusion to be drawn. Furthermore, the current study would have been significantly strengthened with the detailed analyses of more CHD phenotypes. However, as data were retrieved from the hospital authority database, detailed information on coronary disease severity, such as the degree of coronary stenosis, were not available. Owing to the limited plasma samples available for the analysis of adiponectin levels at baseline, adiponectin levels obtained at CRISPS2 were used as an alternative to examine the association with the $+276 \mathrm{G}>\mathrm{T}$ variant and incident $\mathrm{CHD}$ in the current study. However, with the small sample size, in particular the limited number of incident CHD cases, as well as a shorter follow-up interval of $\sim 9.6$ years, we were unable to demonstrate a significant association between CRISPS2 adiponectin level and the development of CHD. Nevertheless, the HRs were in keeping with the protective effect of adiponectin against CHD development in a general population initially free of the disease. Furthermore, we have considered only the most, but not all, confounding factors for the development of CHD. Owing to the observational study design, detailed information on lifestyle modification or treatment interventions, including the effects of different drugs used and changing dosage during the study period, which may act as potential confounding factors, were not available for analyses. 
Taken into consideration, these potential biases, effects of dysglycaemia (including DM, FPG and 2hrG), HT and dyslipidaemia were adjusted for in the multiple adjustment analyses. Other confounding factors in this observational study, such as the effect of attrition, may also lead to potential bias. The CRISPS cohort is a population-based study of the Hong Kong Southern Chinese. The findings from this study may not be generalised to other nations. Nonetheless, our data represent one of the largest longitudinal cohorts of Chinese subjects with a long follow-up period. With the growing epidemic of CHD risk factors, such as DM and hyperlipidaemia, in the Chinese population, the present findings may still be clinically significant. Further prospective studies in Chinese, as well as in other populations, would be useful to validate our results.

In conclusion, this study demonstrated that the $+276 \mathrm{G}>\mathrm{T}$ variant of $A D I P O Q$, associated with low circulating adiponectin levels, may be an independent predictor of CHD in community-based Southern Chinese men initially free of CHD. The current study has provided evidence that a low adiponectin level, as may be affected by a genetic variant in the ADIPOQ gene, confers a greater risk of CHD. Our data are suggestive of a protective role of adiponectin in CHD development in the healthy population. Our findings also support the notion that high adiponectin levels are associated with a lower risk of CHD in healthy populations, whereas high levels in established CVD may reflect a compensatory up-regulation of adiponectin. The $+276 \mathrm{G}>\mathrm{T}$ variant of $A D I P O Q$ may affect the adiponectin gene expression and may act as a potential genetic marker for the prediction of CHD.

\section{Supplementary data}

This is linked to the online version of the paper at http://dx.doi.org/10.1530/ EJE-14-0079.

\section{Declaration of interest}

The authors declare that there is no conflict of interest that could be perceived as prejudicing the impartiality of the research reported.

\section{Funding}

This work was supported by the Hong Kong Research Grant Council (RGC) Theme-Based Research Scheme (TBRS) Grant T12-705/11.

\section{Author contribution statement}

CY Y Cheung and E Y L Hui contributed equally to this work and should be considered as co-first authors. P C Sham and K S L Lam contributed equally to the supervision of this work and are co-corresponding authors. C Y Y Cheung, E Y L Hui, K S L Lam and P C Sham conceived and designed the experiments. K S L Lam initiated and supervised the study. CY Y Cheung performed the experiments and analysed the data. $C Y Y$ Cheung and $E Y L$ Hui wrote the paper. A Xu, Y C Woo, C Y Yeung, K L Ong and $\mathrm{CH} Y$ Fong collected the data and provided advice on experiments and data analysis. K S L Lam, P C Sham, B M Y Cheung, E D Janus and H-F Tse critically revised the manuscript.

\section{Acknowledgements}

The authors would like to thank all the participants of CRISPS and the medical staff of the Department of Health, Hong Kong SAR, for their assistance with data retrieval on life-death status and causes of death.

\section{References}

1 Hui X, Lam KS, Vanhoutte PM \& Xu A. Adiponectin and cardiovascular health: an update. British Journal of Pharmacology 2012165 574-590. (doi:10.1111/j.1476-5381.2011.01395.x)

2 Arita Y, Kihara S, Ouchi N, Takahashi M, Maeda K, Miyagawa J, Hotta K, Shimomura I, Nakamura T, Miyaoka K et al. Paradoxical decrease of an adipose-specific protein, adiponectin, in obesity. Biochemical and Biophysical Research Communications 1999257 79-83. (doi:10.1006/ bbrc.1999.0255)

3 Lam KS \& Xu A. Adiponectin: protection of the endothelium. Current Diabetes Reports 20055 254-259. (doi:10.1007/s11892-005-0019-y)

4 Shargorodsky M, Boaz M, Goldberg Y, Matas Z, Gavish D, Fux A \& Wolfson N. Adiponectin and vascular properties in obese patients: is it a novel biomarker of early atherosclerosis? International Journal of Obesity 200933 553-558. (doi:10.1038/ijo.2009.37)

5 Yamauchi T, Kamon J, Waki H, Imai Y, Shimozawa N, Hioki K, Uchida S, Ito Y, Takakuwa K, Matsui J et al. Globular adiponectin protected ob/ob mice from diabetes and ApoE-deficient mice from atherosclerosis. Journal of Biological Chemistry 2003278 2461-2468. (doi:10.1074/ jbc.M209033200)

6 Koenig W, Khuseyinova N, Baumert J, Meisinger C \& Lowel H. Serum concentrations of adiponectin and risk of type 2 diabetes mellitus and coronary heart disease in apparently healthy middle-aged men: results from the 18-year follow-up of a large cohort from southern Germany. Journal of the American College of Cardiology 200648 1369-1377. (doi:10.1016/j.jacc.2006.06.053)

7 Poehls J, Wassel CL, Harris TB, Havel PJ, Swarbrick MM, Cummings SR, Newman AB, Satterfield S \& Kanaya AM. Association of adiponectin with mortality in older adults: the Health, Aging, and Body Composition Study. Diabetologia 200952 591-595. (doi:10.1007/ s00125-009-1261-7)

8 Wilson SR, Sabatine MS, Wiviott SD, Ray KK, De Lemos JA, Zhou S, Rifai N, Cannon CP \& Morrow DA. Assessment of adiponectin and the risk of recurrent cardiovascular events in patients presenting with an acute coronary syndrome: observations from the Pravastatin Or atorVastatin Evaluation and Infection Trial-Thrombolysis in Myocardial Infarction 22 (PROVE IT-TIMI 22). American Heart Journal 2011 161 1147-1155.e1141. (doi:10.1016/j.ahj.2011.02.014)

9 Qi L, Li T, Rimm E, Zhang C, Rifai N, Hunter D, Doria A \& Hu FB. The +276 polymorphism of the APM1 gene, plasma adiponectin concentration, and cardiovascular risk in diabetic men. Diabetes 2005 54 1607-1610. (doi:10.2337/diabetes.54.5.1607)

10 Gable DR, Matin J, Whittall R, Cakmak H, Li KW, Cooper J, Miller GJ \& Humphries SE. Common adiponectin gene variants show different effects on risk of cardiovascular disease and type 2 diabetes in European subjects. Annals of Human Genetics $2007 \mathbf{7 1}$ 453-466. (doi:10.1111/ j.1469-1809.2006.00340.x) 
11 Pischon T, Pai JK, Manson JE, Hu FB, Rexrode KM, Hunter D \& Rimm EB. Single nucleotide polymorphisms at the adiponectin locus and risk of coronary heart disease in men and women. Obesity $2007 \mathbf{1 5}$ 2051-2060. (doi:10.1038/oby.2007.244)

12 Janus ED. Epidemiology of cardiovascular risk factors in Hong Kong. Clinical and Experimental Pharmacology and Physiology 199724 987-988. (doi:10.1111/j.1440-1681.1997.tb02736.x)

13 Chow WS, Tso AW, Xu A, Yuen MM, Fong CH, Lam TH, Lo SV, Tse HF, Woo YC, Yeung CY et al. Elevated circulating adipocyte-fatty acid binding protein levels predict incident cardiovascular events in a community-based cohort: a 12-year prospective study. Journal of the American Heart Association 20132 e004176. (doi:10.1161/JAHA.112. 004176)

14 Cheung BM, Wat NM, Man YB, Tam S, Thomas GN, Leung GM, Cheng $\mathrm{CH}$, Woo J, Janus ED, Lau CP et al. Development of diabetes in Chinese with the metabolic syndrome: a 6-year prospective study. Diabetes Care 200730 1430-1436. (doi:10.2337/dc06-1820)

15 Alberti KG \& Zimmet PZ. Definition, diagnosis and classification of diabetes mellitus and its complications. Part 1: diagnosis and classification of diabetes mellitus provisional report of a WHO consultation. Diabetic Medicine 199815 539-553. (doi:10.1002/ (SICI) 1096-9136(199807)15:7 < 539::AID-DIA668 > 3.0.CO;2-S)

16 Expert Panel on Detection, Evaluation, and Treatment of High Blood Cholesterol in Adults. Executive Summary of The Third Report of The National Cholesterol Education Program (NCEP) Expert Panel on Detection, Evaluation, And Treatment of High Blood Cholesterol In Adults (Adult Treatment Panel III). Journal of the American Medical Association 2001285 2486-2497. (doi:10.1001/jama.285.19.2486)

$17 \mathrm{Xu}$ A, Chan KW, Hoo RL, Wang Y, Tan KC, Zhang J, Chen B, Lam MC, Tse C, Cooper GJ et al. Testosterone selectively reduces the high molecular weight form of adiponectin by inhibiting its secretion from adipocytes. Journal of Biological Chemistry 2005280 18073-18080. (doi:10.1074/jbc.M414231200)

18 Barth N, Langmann T, Scholmerich J, Schmitz G \& Schaffler A. Identification of regulatory elements in the human adipose most abundant gene transcript-1 (apM-1) promoter: role of SP1/SP3 and TNF- $\alpha$ as regulatory pathways. Diabetologia 200245 1425-1433. (doi:10.1007/s00125-002-0895-5)

19 Zhang D, Ma J, Brismar K, Efendic S \& Gu HF. A single nucleotide polymorphism alters the sequence of SP1 binding site in the adiponectin promoter region and is associated with diabetic nephropathy among type 1 diabetic patients in the Genetics of Kidneys in Diabetes Study. Journal of Diabetes and its Complications 200923 265-272. (doi:10.1016/j.jdiacomp.2008.05.004)

20 Laumen H, Saningong AD, Heid IM, Hess J, Herder C, Claussnitzer M, Baumert J, Lamina C, Rathmann W, Sedlmeier EM et al. Functional characterization of promoter variants of the adiponectin gene complemented by epidemiological data. Diabetes 200958 984-991. (doi:10.2337/db07-1646)

21 Filippi E, Sentinelli F, Romeo S, Arca M, Berni A, Tiberti C, Verrienti A, Fanelli M, Fallarino M, Sorropago G et al. The adiponectin gene SNP+ $276 \mathrm{G}>\mathrm{T}$ associates with early-onset coronary artery disease and with lower levels of adiponectin in younger coronary artery disease patients (age <or=50 years). Journal of Molecular Medicine 200583 711-719. (doi:10.1007/s00109-005-0667-z)

22 Ong KL, Li M, Tso AW, Xu A, Cherny SS, Sham PC, Tse HF, Lam TH, Cheung BM \& Lam KS. Association of genetic variants in the adiponectin gene with adiponectin level and hypertension in Hong Kong Chinese. European Journal of Endocrinology 2010163 251-257. (doi:10.1530/EJE-10-0251)

23 Antonopoulos AS, Tousoulis D, Antoniades C, Miliou A, Hatzis G, Papageorgiou N, Demosthenous M, Tentolouris C \& Stefanadis C. Genetic variability on adiponectin gene affects myocardial infarction risk: the role of endothelial dysfunction. International Journal of Cardiology 2012168 326-330. (doi:10.1016/j.ijcard.2012.09.053)

24 Gui MH, Li X, Jiang SF, Gao J, Lu DR \& Gao X. Association of the adiponectin gene rs1501299 $\mathrm{G}>\mathrm{T}$ variant, serum adiponectin levels, and the risk of coronary artery disease in a Chinese population. Diabetes Research and Clinical Practice 201297 499-504. (doi:10.1016/j.diabres. 2012.05.011)

25 Bottner A, Kratzsch J, Muller G, Kapellen TM, Bluher S, Keller E, Bluher M \& Kiess W. Gender differences of adiponectin levels develop during the progression of puberty and are related to serum androgen levels. Journal of Clinical Endocrinology and Metabolism 200489 4053-4061. (doi:10.1210/jc.2004-0303)

26 Purcell S, Cherny SS \& Sham PC. Genetic power calculator: design of linkage and association genetic mapping studies of complex traits. Bioinformatics 200319 149-150. (doi:10.1093/bioinformatics/19.1.149)

27 Hara K, Boutin P, Mori Y, Tobe K, Dina C, Yasuda K, Yamauchi T, Otabe S, Okada T, Eto K et al. Genetic variation in the gene encoding adiponectin is associated with an increased risk of type 2 diabetes in the Japanese population. Diabetes 200251 536-540. (doi:10.2337/diabetes. 51.2.536)

28 Ramya K, Ayyappa KA, Ghosh S, Mohan V \& Radha V. Genetic association of ADIPOQ gene variants with type 2 diabetes, obesity and serum adiponectin levels in south Indian population. Gene $2013 \mathbf{5 3 2}$ 253-262. (doi:10.1016/j.gene.2013.09.012)

29 Arikoglu H, Ozdemir H, Kaya DE, Ipekci SH, Arslan A, Kayis SA \& Gonen MS. The adiponectin variants contribute to the genetic background of type 2 diabetes in Turkish population. Gene 2014534 10-16. (doi:10.1016/j.gene.2013.10.039)

30 Matsuzawa Y, Funahashi T, Kihara S \& Shimomura I. Adiponectin and metabolic syndrome. Arteriosclerosis, Thrombosis, and Vascular Biology 200424 29-33. (doi:10.1161/01.ATV.0000099786.99623.EF)

31 Nishizawa H, Shimomura I, Kishida K, Maeda N, Kuriyama H, Nagaretani H, Matsuda M, Kondo H, Furuyama N, Kihara S et al. Androgens decrease plasma adiponectin, an insulin-sensitizing adipocyte-derived protein. Diabetes 200251 2734-2741. (doi:10.2337/ diabetes.51.9.2734)

32 Cooper DN. Functional intronic polymorphisms: buried treasure awaiting discovery within our genes. Human Genomics 20104 284-288. (doi:10.1186/1479-7364-4-5-284)

33 Majewski J \& Ott J. Distribution and characterization of regulatory elements in the human genome. Genome Research 200212 1827-1836. (doi:10.1101/gr.606402)

Received 28 January 2014

Revised version received 3 April 2014

Accepted 22 April 2014 